\title{
Efeito da aplicação de zinco via foliar na síntese de triptofano, aminoácidos e proteínas solúveis em mudas de cafeeiro
}

\author{
Marcelo Ribeiro Malta ${ }^{1}$, Antônio Eduardo Furtini Neto² ${ }^{2}$ José Donizeti Alves ${ }^{3}$, \\ Paulo Tácito Gontijo Guimarães ${ }^{4}$
}

\begin{abstract}
${ }^{1}$ Empresa de Pesquisa Agropecuária de Minas Gerais, CP 176, 37200-000, Lavras, MG, Brasil; ${ }^{2}$ Departamento de Ciência do Solo, Universidade Federal de Lavras, 37200-000, Lavras, MG, Brasil; 3 Departamento de Biologia, Universidade Federal de Lavras, 37200-000, Lavras, MG, Brasil, " Empresa de Pesquisa Agropecuária de Minas Gerais, CP 176, 37200-000, Lavras, MG, Brasil
\end{abstract}

Avaliou-se, neste trabalho, o efeito da aplicação de Zn via foliar na síntese de triptofano, aminoácidos totais e proteínas solúveis totais em mudas de cafeeiro (Coffea arabica L.). Cultivaram-se as mudas em solução nutritiva sem Zn durante quatro meses e após esse período, pulverizaram-se as plantas com $\mathrm{ZnSO}_{4} \cdot 7 \mathrm{H}_{2} \mathrm{O}$ a $0,6 \%$, definindo-se os tratamentos segundo a posição de aplicação (basal: 6 pares de folhas inferiores, ou apical: 6 pares de folhas superiores, além dos ramos plagiotrópicos). As plantas foram coletadas nos tempos: 0 (testemunha), 12, 24, 48 ou $72 \mathrm{~h}$ após aplicação de $\mathrm{Zn}$, separando-se as folhas da região apical, basal e dos ramos plagiotrópicos. Determinaram-se as concentrações foliares de triptofano, aminoácidos totais e proteínas solúveis totais. Pelos resultados, observou-se redução na concentração de triptofano e aumento na concentração de aminoácidos totais e proteínas solúveis totais após a pulverização com Zn.

Palavras-chave: Coffea arabica, metabolismo, proteína, triptofano.

Effect of zinc application on tryptophan synthesis, total amino acids and total soluble proteins of leaves of coffee seedlings: An experiment was conducted aiming to evaluate the effect of the application of $\mathrm{Zn}$ on tryptophan synthesis, total amino acids and total soluble proteins of leaves of coffee seedlings (Coffea arabica L.). The seedlings were grown in nutrient solution without $\mathrm{Zn}$ for a four-month period. After that time treatments were applied. The plants were sprayed with $0.6 \% \mathrm{ZnSO}_{4} .7 \mathrm{H}_{2} \mathrm{O}$ in three different regions (basal: 6 pairs of lower leaves; apical: 6 pairs of upper leaves; and plagiotropic branches). The plants were harvested at times: 0 (control), 12, 24, 48 or $72 \mathrm{~h}$ after application of $\mathrm{Zn}$. The leaves were then separated into lots taken from the basal as well as from the plagiotropic branches. These were analysed for tryptophan, concentration, total amino acids and total soluble proteins. From the results obtained a reduction in the tryptophan concentration was observed following $\mathrm{Zn}$ application together with an increase in the concentration of total amino acids and total soluble proteins

Key words: Coffea arabica, metabolism, protein, triptophan.

\section{INTRODUÇÃO}

Todas as deficiências nutricionais interferem no crescimento e desenvolvimento das plantas, mas a de zinco (Zn) é tão acentuada que termos como "folha pequena" e "formação de roseta" têm constantemente sido aplicados a essa condição (Epstein, 1975). Grande parte dos sintomas de deficiência de Zn está associada a distúrbios no metabolismo das auxinas, principalmente do ácido indolilacético (AIA), fitormônio responsável pelo crescimento das plan- tas. O modo de ação do $\mathrm{Zn}$ no metabolismo das auxinas ainda não está bem esclarecido (Epstein, 1975; Faquin, 1994; Marschner, 1995), e admite-se, entretanto, que o Zn seja necessário para a síntese do triptofano (Trp), aminoácido precursor do AIA (Válio, 1979; Mengel e Kirkby, 1987). Quando o Trp é fornecido ao ápice de coleóptilos, rapidamente é metabolizado em AIA. Algumas plantas deficientes em $\mathrm{Zn}$ apresentam concentrações muito baixas de AIA, podendo ter seu crescimento normalmente 
reativado pela aplicação de Trp ou AIA (Válio, 1979). Já em 1948, em um estudo com tomateiro, verificou-se que em plantas com deficiência de $\mathrm{Zn}$ havia redução na alongação, baixa atividade da auxina e baixo conteúdo de Trp (Tsuí, 1948). Salami e Kenefick (1970), trabalhando com milho em solução nutritiva, observaram que os sintomas de deficiência de $\mathrm{Zn}$ podem ser eliminados se for adicionado Zn ou Trp à solução nutritiva, o que é uma evidência indireta da necessidade do Zn para manter teores adequados de Trp.

Outros autores afirmam que, em plantas deficientes em Zn, há um acúmulo de Trp. Em estudos com cafeeiros deficientes em Zn, Ramaiah et al. (1964) observaram um acúmulo da maioria dos aminoácidos identificados. Segundo esses autores, os resultados sugerem que um acúmulo de alguns aminoácidos em concentrações tóxicas, no caso de deficiência antes da aparição de sintomas visuais na planta, poderia explicar as anormalidades foliares que surgem nas brotações subseqüentes. Sugerem, também, que a maior concentração de Trp em folhas deficientes em Zn, e sua menor concentração em folhas normais, pode ser explicada como um possível distúrbio causado no sistema catalítico na "conversão" do Trp para AIA nas plantas deficientes. Takaki e Kushizaki (1970), Mohideen et al. (1994) e Domingo et al. (1992) também encontraram altos teores de Trp em plantas deficientes em $\mathrm{Zn}$.

Em tais plantas há desestruturação dos ribossomos citoplasmáticos (Prask e Plocke, 1971), a qual promove redução do conteúdo ribossomal e, consequentemente, da síntese protéica (Kitagishi et al., 1987; Obata e Umebayashi, 1988; Marschner, 1995), levando ao acúmulo de aminoácidos livres (Kitagishi e Obata, 1986; Marschner, 1995). O Zn está estreitamente envolvido no metabolismo de nitrogênio nas plantas e, consequentemente, na síntese proteíca (Tsui, 1948; Malavolta, 1980; Mengel e Kirby, 1987; Faquin, 1994). Ramaiah et al. (1964) observaram que os teores de proteínas formadas em folhas de cafeeiros com deficiência em $\mathrm{Zn}$ foram menores que em folhas normais.

O Zn controla a atividade da enzima RNAse que hidrolisa o RNA, causando a diminuição da síntese protéica, atuando na multiplicação celular, proporcionando menor número e tamanho de células e reduzindo o comprimento de internódios (Malavolta, 1986). Há clara correlação inversa entre o fornecimento de Zn e a atividade da RNAse e também entre a atividade da RNAse e o conteúdo de proteínas e o crescimento da planta (Marschner, 1995).
Apesar das muitas pesquisas realizadas, ainda existem informações conflitantes em relação ao metabolismo do $\mathrm{Zn}$, existindo controvérsias se a deficiência deste nutriente pode afetar direta e indiretamente o metabolismo do cafeeiro. Segundo vários autores, o Zn é responsável direto pela síntese do Trp, um precursor do AIA, e indireto pela síntese de proteínas. Com base nas observações e questionamentos citados, este trabalho teve como objetivo avaliar o efeito da aplicação de Zn via foliar na síntese de Trp, aminoácidos totais e proteínas solúveis totais em mudas de cafeeiro.

\section{MATERIAL E MÉTODOS}

Desenvolveu-se o experimento em casa de vegetação do Departamento de Ciência do Solo da Universidade Federal de Lavras, de julho a novembro de 1999. Utilizouse um delineamento inteiramente casualizado, com os tratamentos distribuídos em fatorial $4 \times 2$, sendo o primeiro fator quatro tempos de coleta após a aplicação de Zn (12, 24,48 e 72 h), e o segundo fator, duas posições de aplicação (ápice ou base) na planta, além da testemunha (tempo de coleta 0, porém sem aplicação de Zn). Empregaram-se quatro repetições, sendo cada parcela constituída por um vaso com capacidade de $3 \mathrm{dm}^{3}$, contendo duas plantas de cafeeiro.

As mudas de cafeeiro (Coffea arabica L.) utilizadas foram do cv. Acaiá do Cerrado MG 1474, com seis meses de idade no início do experimento. Antes de transplantálas para os vasos, foram levadas a uma casa de vegetação para aclimatarem-se. Após duas semanas, foram retiradas dos sacos plásticos, selecionadas e após as raízes terem sido lavadas com água para eliminar os resíduos do substrato, foram transplantadas, mantendo-se duas plantas por vaso.

O experimento foi conduzido em solução nutritiva segundo Hoagland e Arnon (1950). O pH da solução nutritiva, trocada semanalmente, foi ajustado em 5,5 $\pm 0,5$. A aeração foi mantida constante, assim como o volume de solução, por meio de adição de água deionizada. As mudas, inicialmente, foram tratadas com solução nutritiva diluída sem Zn, durante 30 dias. Nos primeiros 15 dias, a solução estava diluída na proporção $1 / 4$ e, nos próximos 15 dias, foi elevada para a diluição 1/1. Depois deste período, foi fornecida a solução nutritiva sem diluição e sem $\mathrm{Zn}$.

Quatro meses após o início do cultivo, aplicaram-se os tratamentos. As plantas foram pulverizadas com solu- 
ção $0,6 \% \mathrm{ZnSO}_{4} \cdot 7 \mathrm{H}_{2} \mathrm{O}$, contendo espalhante adesivo Agril a $0,03 \%$. Cada planta recebeu $15 \mathrm{~mL}$ dessa solução, pulverizada nas superfícies adaxial e abaxial das folhas, segundo a posição de aplicação (basal: 6 pares de folhas inferiores ou apical: 6 pares de folhas superiores, além dos ramos plagiotrópicos), conforme figura 1. As plantas foram coletadas nos tempos: 0 (testemunha), 12, 24, 48 ou $72 \mathrm{~h}$ após a pulverização com $\mathrm{Zn}$. As folhas foram divididas naquelas da região apical, basal e dos ramos plagiotrópicos. Todas as folhas foram lavadas em água corrente e posteriormente em água deionizada. Essas amostras foram congeladas em $\mathrm{N}_{2}$ líquido e mantidas à $-80^{\circ} \mathrm{C}$ até a sua utilização.

Para as análises da concentração de proteínas solúveis totais, obtiveram-se extratos mediante a maceração em almofariz sob baixa temperatura $\left(4{ }^{\circ} \mathrm{C}\right)$ de $1 \mathrm{~g}$ de limbo foliar em $5 \mathrm{~mL}$ do meio de extração (tampão $0,1 \mathrm{M}$ Tris $\mathrm{HCl}, \mathrm{pH} 7,5,50 \mathrm{mM} \mathrm{NaCl}, 5 \mathrm{mM} \mathrm{MgCl} .6 \mathrm{H}_{2} \mathrm{O}, 1 \mathrm{mM}$ PMSF (fluoreto de fenilmetilsulfonil). Após a maceração, o material foi centrifugado a $10.000 \mathrm{rpm}$ durante $30 \mathrm{~min}$, a $4{ }^{\circ} \mathrm{C}$. Após a centrifugação, o sobrenadante foi reservado a $-20{ }^{\circ} \mathrm{C}$, para posterior determinação das proteínas solúveis e aminoácidos.

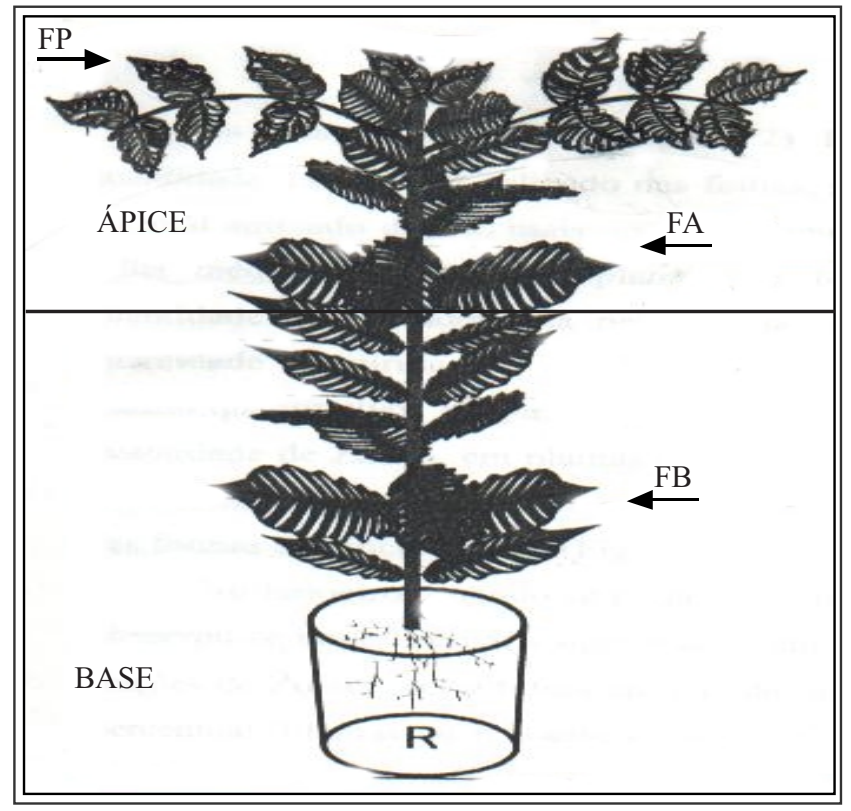

Figura 1. Representação esquemática da divisão das mudas de cafeeiro na pulverização e coleta: $\mathrm{FA}=$ folhas da região apical; $\mathrm{FB}=$ folhas da região basal; $\mathrm{FP}=$ folhas dos ramos plagiotrópicos.
Quantificou-se a concentração de proteínas solúveis pelo método de Bradford (1976). A curva padrão foi obtida com soroalbumina bovina (BSA). A concentração de aminoácidos totais foi dosada de acordo com o método de Yemm e Coccking (1955), utilizando-se glicina na curva padrão.

A concentração de Trp foi determinada segundo método do Centro Nacional de Pesquisa de Milho e Sorgo (CNPMS-EMBRAPA), adaptada de Hernandez e Bates (1969) e Ortega e Bates (1983). O extrato foi obtido mediante a maceração em almofariz sob baixa temperatura (4 ${ }^{\circ} \mathrm{C}$ ) de $1 \mathrm{~g}$ de limbo foliar em 4,0 $\mathrm{mL}$ de acetato de sódio

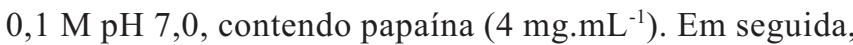
esse extrato foi transferido para tubos de hidrólise com tampa e homogeneizado em agitador orbital de tubos. Esse material foi incubado a $63{ }^{\circ} \mathrm{C} \pm 2{ }^{\circ} \mathrm{C}$ por $16 \mathrm{~h}$, sendo agitado quatro vezes a cada $30 \mathrm{~min}$. Após resfriamento à temperatura ambiente e centrifugado a $2.500 \mathrm{rpm}$ por $5 \mathrm{~min}$, transferiu-se $1 \mathrm{~mL}$ do hidrolisado para tubo de ensaio e adicionaram-se $4 \mathrm{~mL}$ do reagente de Salkowski. Agitou-se vigorosamente em agitador orbital de tubos, e incubou-se a $63{ }^{\circ} \mathrm{C} \pm 2{ }^{\circ} \mathrm{C}$ por $15 \mathrm{~min}$. Resfriou-se à temperatura ambiente e fez-se a leitura em espectrofotômetro a $560 \mathrm{~nm}$. O cálculo da concentração de Trp foi obtido mediante a equação: $\operatorname{Trp}=[50 \times$ (Abs.) $-0,018] / \%$ proteína.

\section{RESULTADOS E DISCUSSÃO}

Ocorreu redução nas concentrações médias de Trp até $72 \mathrm{~h}$ após a pulverização, em relação aos tempos de coleta anteriores, independentemente da posição de aplicação (figura 2A) e da posição de coleta (figura 2B e tabela 1). Também Mohideen et al. (1994), em pesquisas realizadas com milho, tomate e arroz, em solução nutritiva na ausência e na presença de $\mathrm{Zn}$, observaram pequenas quantidades de Trp em plantas cultivadas na presença de $\mathrm{Zn}$; entretanto, a concentração deste aminoácido foi muito pequena quando comparada à concentração daquelas plantas crescidas em solução nutritiva sem Zn. Do mesmo modo, Salami e Kenefick (1970) e Domingo et al. (1992) encontraram em milho e rabanete, cultivados em hidropônica, altas concentrações de Trp em plantas deficientes em $\mathrm{Zn}$. Esses autores concluíram que o $\mathrm{Zn}$ é requerido no metabolismo do Trp à auxina via triptamina, amina biogênica, formada a partir da descarboxilação do Trp. Entretanto, esses resultados não estão de acordo com Tsuí (1948), que afirma ser o Zn essencial para a síntese do Trp. Em um cultivo 
de tomateiro, esse autor observou em plantas que apresentavam deficiência deste nutriente, redução na alongação de ramos, uma baixa atividade de AIA e um baixo conteúdo de Trp, contrariando os resultados aqui apresentados.
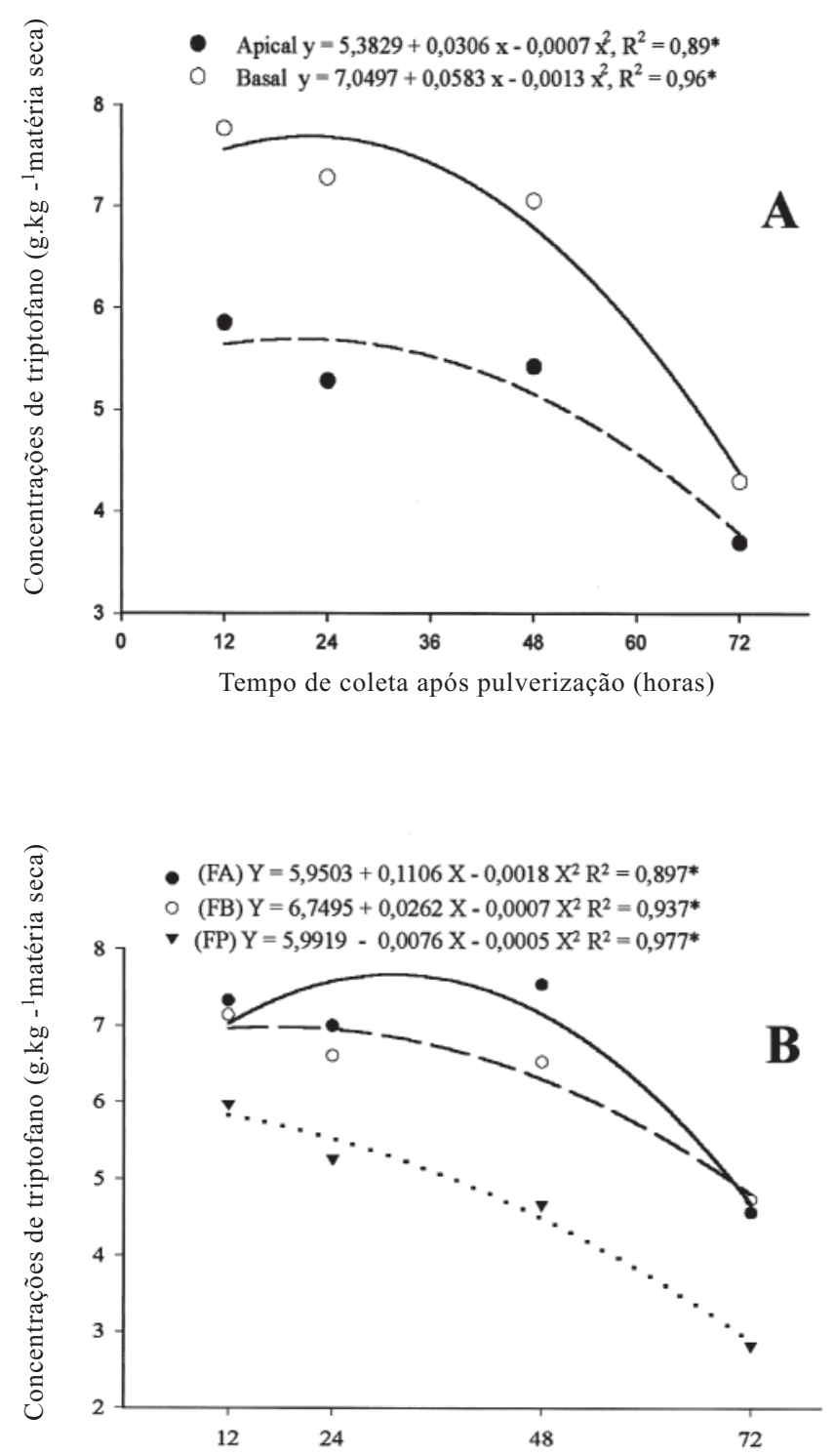

Tempo de coleta após pulverização (horas)

Figura 2. Concentrações médias de Trp nas posições de aplicação (A), basal ou apical, e nas posições de coleta (B), em função dos tempos de absorção foliar de $\mathrm{Zn}$ por mudas de cafeeiro. Folhas apicais $=$ FA, Folhas basais $=$ $\mathrm{FB}$, Folhas dos ramos plagiotrópicos $=\mathrm{FP}$. * indica significância a $5 \%$ pelo teste $\mathrm{F}$.
Tabela 1. Concentrações médias de Trp (g. $\mathrm{kg}^{-1}$ de matéria seca) em mudas de cafeeiro, em função dos tempos de absorção foliar de $\mathrm{Zn}$, nas diferentes posições de coleta.

\begin{tabular}{lccc}
\hline \multirow{2}{*}{$\begin{array}{c}\text { Tempo } \\
\text { (horas) }\end{array}$} & \multicolumn{3}{c}{ Posições de coleta } \\
\cline { 2 - 4 } FA $^{\mathrm{a}}$ & $\mathrm{FP}$ & $\mathrm{FB}$ \\
\hline 12 & $7,33 \mathrm{a}$ & $5,97 \mathrm{~b}$ & $7,14 \mathrm{a}$ \\
24 & $7,00 \mathrm{a}$ & $5,26 \mathrm{~b}$ & $6,61 \mathrm{a}$ \\
48 & $7,54 \mathrm{a}$ & $4,66 \mathrm{c}$ & $6,53 \mathrm{~b}$ \\
72 & $4,45 \mathrm{a}$ & $2,82 \mathrm{~b}$ & $4,72 \mathrm{a}$ \\
\hline
\end{tabular}

${ }^{\mathrm{a}} \mathrm{FA}$ - Folhas apicais, FP - Folhas dos ramos plagiotrópicos, FB - Folhas basais. Médias de 4 repetições. Médias seguidas pela mesma letra na linha não diferem entre si.

De modo geral, as maiores concentrações de aminoácidos foram observadas nas folhas da região superior das mudas de cafeeiro, independentemente da posição de pulverização do Zn (figura 3 e tabela 2). Esse comportamento pode ser explicado pelo fato das folhas superiores serem mais novas, e, por isso, metabolicamente mais ativas que as basais, contribuindo, assim, para maior concentração de aminoácidos nesses órgãos.

O acúmulo de aminoácidos livres em plantas deficientes em Zn foi verificado por Kitagishi e Obata (1986) e Marschner (1995). Ramaiah et al. (1964) também observaram acúmulo na maioria dos aminoácidos identificados em cafeeiros deficientes em $\mathrm{Zn}$. Esse comportamento não foi observado neste experimento. O que se pôde perceber foi que, de maneira geral, houve aumento na concentração de aminoácidos $12 \mathrm{~h}$ após a pulverização de $\mathrm{Zn}$ em relação à testemunha e uma queda nessa concentração no tempo de coleta $24 \mathrm{~h}$, e, após esse intervalo de tempo, houve novamente aumento na concentração de aminoácidos (tabela 2).

Observando-se as concentrações médias de proteínas nas posições de aplicação basal ou apical (figura 4A) e nas diferentes posições de coleta (figura 4B), em função dos tempos de coleta, nota-se que há um aumento nas concentrações de tais substâncias até $72 \mathrm{~h}$ após a aplicação do Zn, ocasião em que são observadas as maiores concentrações de proteínas, independentemente da posição de aplicação e posição coletada. Prask e Plocke (1971) argumentam que em plantas deficientes em Zn há uma redução do conteúdo ribossomal, com consequente redução da síntese protéica, gerando acúmulo de aminoácidos livres. Malavolta (1980) e Mengel e Kirkby (1987) afirmam que o Zn está estreitamente envolvido no metabolismo nitrogenado e, 

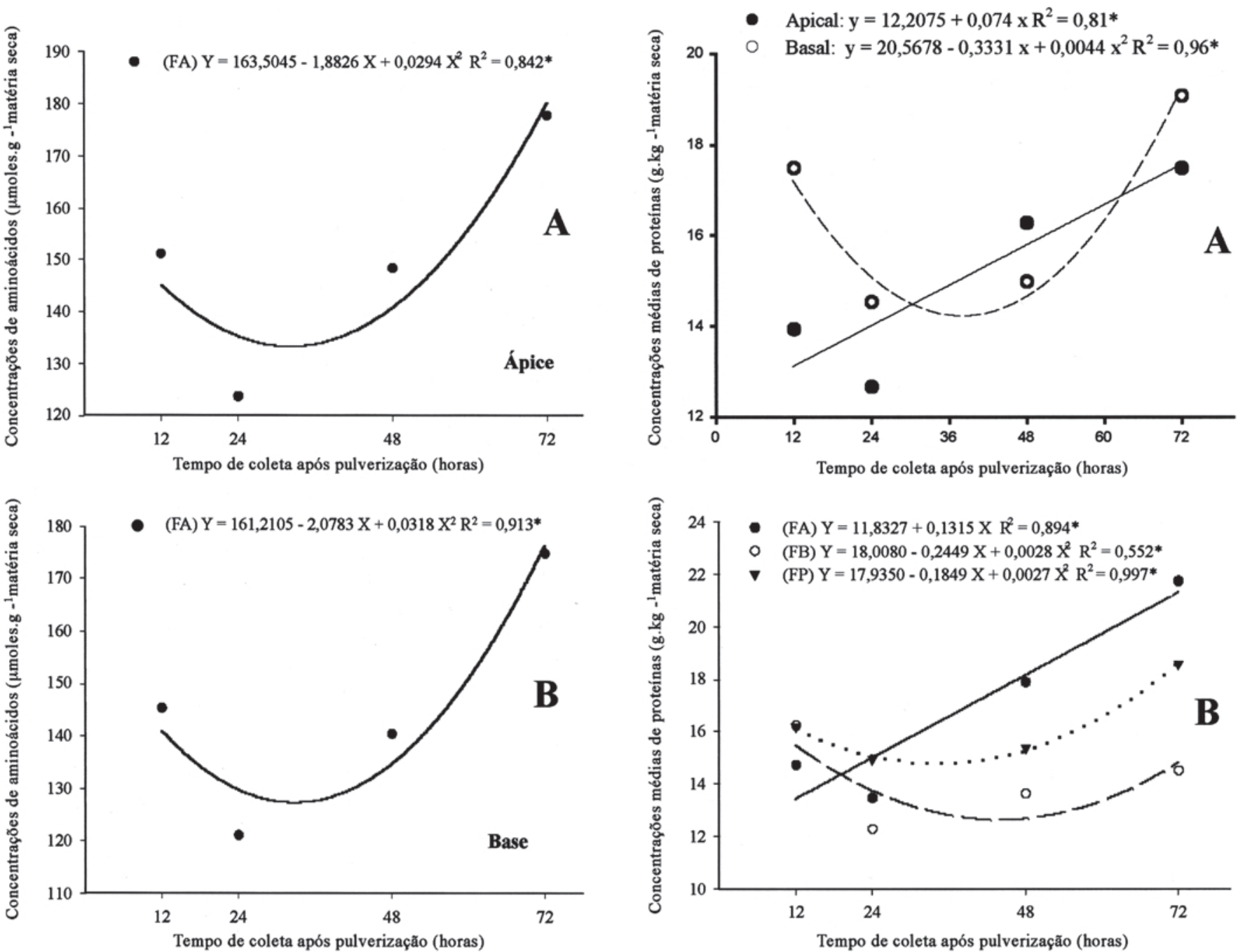

Figura 3. Concentrações médias de aminoácidos na posição de coleta folhas apicais (FA), nas posições de aplicação apical ou basal, em função dos tempos de coletas após a pulverização com $\mathrm{Zn}$ em mudas de cafeeiro. * indica significância a $5 \%$ pelo teste $\mathrm{F}$.

Figura 4. Concentrações médias de proteínas nas posições de aplicação (A), ápice ou base, e nas posições de coleta (B), em função dos tempos de absorção foliar de $\mathrm{Zn}$ por mudas de cafeeiro. Folhas apicais $=$ FA, Folhas basais $=$ $\mathrm{FB}$, Folhas dos ramos plagiotrópicos $=\mathrm{FP}$. ${ }^{*}$ indica significância a $5 \%$ pelo teste $\mathrm{F}$.

Tabela 2. Concentrações médias de aminoácidos ( $\mu$ moles $\mathrm{g}^{-1}$ de matéria seca) em mudas de cafeeiro, em função dos tempos de absorção foliar de $\mathrm{Zn}$, nas diferentes posições de coleta, quando o $\mathrm{Zn}$ foi aplicado na posição basal ou apical.

\begin{tabular}{|c|c|c|c|c|c|c|}
\hline \multirow{2}{*}{$\begin{array}{l}\text { Tempos } \\
\text { (horas) }\end{array}$} & \multicolumn{3}{|c|}{ Apical } & \multicolumn{3}{|c|}{ Basal } \\
\hline & $\mathrm{FA}^{\mathrm{a}}$ & FP & FB & FA & FP & FB \\
\hline 0 & 129,63 & 139,05 & 102,72 & 129,63 & 139,05 & 102,72 \\
\hline 12 & $151,26 \mathrm{~b}$ & $173,02 \mathrm{a}$ & $136,91 b$ & $145,39 b$ & $174,83 a$ & $153,8 b$ \\
\hline 24 & $123,77 \mathrm{a}$ & $132,02 \mathrm{a}$ & $98,08 \mathrm{~b}$ & $121,15 b$ & $154,27 \mathrm{a}$ & $79,91 \mathrm{c}$ \\
\hline 48 & $148,46 b$ & $188,75 \mathrm{a}$ & $111,85 \mathrm{c}$ & $140,43 b$ & $160,19 a$ & $121,8 b$ \\
\hline 72 & $177,93 \mathrm{a}$ & $158,21 \mathrm{a}$ & $106,36 b$ & $174,81 \mathrm{a}$ & $172,25 \mathrm{a}$ & $96,84 b$ \\
\hline
\end{tabular}

${ }^{a}$ FA - Folhas apicais, FP - Folhas dos ramos plagiotrópicos, FB - Folhas basais. Médias de 4 repetições. Médias seguidas pela mesma letra na linha não diferem entre si. 
consequentemente, na síntese protéica. Além dos autores citados que corroboram a redução da síntese protéica em plantas deficientes em Zn, Ramaiah et al. (1964) reforçam essas considerações ao observar que os teores de proteína formados em folhas de cafeeiros com deficiência em $\mathrm{Zn}$ foram menores que em folhas que receberam fornecimento adequado do nutriente. No presente trabalho, observou-se que as concentrações de proteínas em mudas de cafeeiro que não foram pulverizadas com $\mathrm{Zn}$ foram menores que nas que receberam pulverização, sendo nítidas essas diferenças $72 \mathrm{~h}$ após as pulverizações, principalmente nas folhas da região superior da planta (tabela 3). Essa tendência de maior concentração de proteínas na região apical pode ser explicada por serem as folhas dessa região mais novas e, portanto, metabolicamente mais ativas que as basais. Longnecker e Robson (1993) relatam que tecidos jovens tendem a acumular, preferencialmente, mais $\mathrm{Zn}$ que os maduros, pois representam regiões metabolicamente mais ativas, com grande demanda por nutrientes. Como o Zn é necessário para a síntese protéica, era de esperar que a região apical apresentasse maior concentração de proteínas.

Segundo Malavolta (1986), o Zn está envolvido no metabolismo das proteínas controlando a atividade da enzima RNAse que hidrolisa o RNA, causando diminuição na síntese protéica, atuando na multiplicação celular, proporcionando menor número e tamanho de células, reduzindo o comprimento de internódios. Marschner (1995) cita que há correlação inversa entre o fornecimento de $\mathrm{Zn}$ e a atividade da RNAse e também entre a atividade da RNAse e o conteúdo de proteínas e o crescimento da planta, corroborando os resultados do presente trabalho.

Tabela 3. Concentrações médias de proteínas (g. $\mathrm{kg}^{-1}$ de matéria seca) em mudas de cafeeiro, em função dos tempos de absorção foliar de Zn, nas diferentes posições de coleta.

\begin{tabular}{cccc}
\hline \multirow{2}{*}{$\begin{array}{l}\text { Tempo } \\
\text { (horas) }\end{array}$} & \multicolumn{3}{c}{ Posições de coleta } \\
\cline { 2 - 4 } & FA & FP & FB \\
\hline 0 & 13,50 & 11,86 & 13,90 \\
12 & $14,73 \mathrm{a}$ & $16,17 \mathrm{a}$ & $16,24 \mathrm{a}$ \\
24 & $13,46 \mathrm{a}$ & $14,93 \mathrm{a}$ & $12,29 \mathrm{a}$ \\
48 & $17,90 \mathrm{a}$ & $15,36 \mathrm{~b}$ & $13,63 \mathrm{~b}$ \\
72 & $21,75 \mathrm{a}$ & $18,58 \mathrm{~b}$ & $14,52 \mathrm{c}$ \\
\hline
\end{tabular}

${ }^{a}$ FA - Folhas apicais, FP - Folhas dos ramos plagiotrópicos, FB - Folhas basais. Médias de 4 repetições. Médias seguidas pela mesma letra na linha não diferem entre si.

\section{REFERÊNCIAS}

Bradford MM (1976) A rapid and sensitive method for the quantification of microgram quantities of protein utilizing the principle of protein-dye binding. Anal. Biochem. 72:248-254.

Domingo A, Nagatomo Y, Tamai M, Takaki H (1992) Freetryptophan and indolacetic acid in zinc-deficient radish shoots. Soil Sci. Plant Nutr. 38:261-267.

Epstein M (1975) Nutrição mineral das plantas: princípios e perspectivas.: USP/Livros Técnicos e Científicos, São Paulo.

Faquin V (1994) Nutrição mineral de plantas. ESAL/ FAEPE, Lavras.

Hernandez HH, Bates LS (1969) A modified method for rapid tryptophan analysis in maize. CIMMYT, México City (Research Bulletin, 13).

Hoagland DR, Arnon DI (1950) The water-culture method for growing plants without soil.: Califórnia Agricultural Experiment Station, Berkeley 32p. (Circular 347).

Kitagishi K, Obata H (1986) Effects of zinc deficiency on the nitrogen metabolism of meristematic tissue of rice plants with reference to protein synthesis. Soil Sci. Plant Nutr. 32:397-405.

Kitagishi K, Obata H, Kondo T (1987) Effect of zinc deficiency on 80 s ribossome content of meristematic tissue of rice plant. Soil Sci. Plant Nutr. 33:423-429.

Longnecker NE, Robson AD (1993) Distribution and transport of zinc in plants. In: Robson AD (ed), Zinc and soil and plants. pp.79-81. Kluwer Academic Publishers, Dordrecht.

Malavolta E (1980) Elementos de nutrição mineral de plantas. Ceres, São Paulo.

Malavolta E (1986) Nutrição, adubação e calagem para o cafeeiro. In: Rena A B, Malavolta E, Rocha M, Yamada $\mathrm{T}$ (eds), Cultura do cafeeiro: fatores que afetam a produtividade. pp.165-275. Associação Brasileira para Pesquisa da Potassa e do Fosfato, Piracicaba.

Marschner H (1995) Mineral nutrition of higher plants. Academic Press, San Diego.

Mengel K, Kirkby EA (1987) Principles of plant nutrition. $4^{\text {th }}$ edn. Internacional Potash Institute, Berna.

Mohideen JS, Hossain B, Nagatomo Y, Tamai M, Takaki H (1994) Effect of zinc deficiency on the concentration of free tryptophan at different growth stages in higher plants. Bull. Fac. Agric. Miyazaki Univ. 41:1-9. 
Obata H, Umebayashi M (1988) Effect of zinc deficiency on protein synthesis in cultured tobaco plant cells. Soil Sci. Plant Nutr. 34:351-357.

Ortega EI, Bates LS (1983) Biochemical and agronomic studies of two modified hard-endosperm opaque-2 maize (Zea mays) populations. Cereal Chem. 60:107-111.

Prask JA, Plocke DJ (1971) A Role for Zinc in the structural integrity of the cytoplasmic ribosomes of Euglena gracilis. Plant Physiol. 48:150-155.

Ramaiah PK, Rao MVK, Chokkanna NG (1964) Zinc deficiency and aminoacids of coffee leaves. Turrialba 14:136-139.
Salami AU, Kenefick DG (1970) Stimulation of growth in zinc-deficient corn seedlings by the addition of tryptophan. Crop Sci. 10:291-294.

Takaki H, Kushizaki M (1970) Acumulation of free tryptophan and tryptamine in zinc deficient plants. Plant Cell Physiol. 11:793-804.

Tsui C (1948) The role of zinc in auxin synthesis in the tomato plant. Am. J. Bot. 35:172-180.

Válio IFM (1979). Auxinas. In: Ferri MG (ed), Fisiologia Vegetal, pp.39-72. EPU, São Paulo.

Yemm EW, Coccking EC (1955) The determination of amino acid with ninhydrin. Analyst 80: 209-213. 